\title{
Curative 3D Conformal Radiotherapy of Non-Operated Prostate Adenocarcinoma at Pointe-a-Pitre University Hospital (Guadeloupe): About 29 Cases
}

\author{
Ibrahima Thiam ${ }^{*}$, Kanta $\mathrm{Ka}^{2 *}$, Awa Sadikh Badiane', Mouhamadou Bachir Bấ \\ El Hadj Amadou Sall1, Boucar Ndong3, Papa Ahmet Fall3,4, Mamadou Moustapha Dieng1,3, \\ Papa Macoumba Gaye ${ }^{2,3}$
}

${ }^{1}$ Joliot Curie Institute of Aristide Le Dantec Hospital, Dakar, Senegal ${ }^{2}$ Radiotherapy Department of the University Hospital Center of Dalal Jamm, Guédiawaye, Senegal ${ }^{3}$ Cheikh Anta Diop University, Dakar, Senegal ${ }^{4}$ Urology Department of the University Hospital Center of Dalal Jamm, Guédiawaye, Senegal Email: Ibathiam29@gmail.com,ka.kanta04@gmail.com, awasadikh@gmail.com,mbbachir21@gmail.com, asall.jr@gmail.com, ndongboucar73@yahoo.fr,papaahmed2@gmail.com,moustaphamamadou@gamil.com,macoumba.gaye@gmail.com

How to cite this paper: Thiam, I., Ka, K., Badiane, A.S., Bâ, M.B., Sall, E.H.A., Ndong, B., Fall, P.A., Dieng, M.M. and Gaye, P.M. (2021) Curative 3D Conformal Radiotherapy of Non-Operated Prostate Adenocarcinoma at Pointe-a-Pitre University Hospital (Guadeloupe): About 29 Cases. Journal of Cancer Therapy, 12, 279-288. https://doi.org/10.4236/jct.2021.125026

Received: April 12, 2021

Accepted: May 24, 2021

Published: May 27, 2021

Copyright $\odot 2021$ by author(s) and Scientific Research Publishing Inc. This work is licensed under the Creative Commons Attribution International License (CC BY 4.0).

http://creativecommons.org/licenses/by/4.0/

\section{Abstract}

Context: Technological advances have improved the toxicities of radiotherapy. We are evaluating the 3D technique in prostate cancer. Materials and Methods: Retrospective study from January 2015 to December 2015 with 29 files. Survival was calculated by Kaplan-Meier method. Results: We collected 29 patient records over the study period. The median age was 75 years with the following extremes: 54 years and 83 years. The median PSA level was 12 $\mathrm{ng} / \mathrm{ml}$ with a range of 3.05 to $79 \mathrm{ng} / \mathrm{ml}$. Gleason score analysis showed $6 \mathrm{pa}$ tients $(20.69 \%)$ with a score of $6(3+3), 23$ patients $(79.31 \%)$ with a score of 7 including 12 patients (41.38\%) with grade 3 and 11 patients $(37.93 \%)$ with grade 4 . The median dose delivered was $74 \mathrm{~Gy}$, with a mean dose of $73.79 \mathrm{~Gy}$ and extremes of $70 \mathrm{~Gy}$ for the minimum and $76 \mathrm{~Gy}$ for the maximum. Hormone therapy was combined with radiotherapy in 17 patients (58.62\%). Seven patients $(24.14 \%)$ had grade 1 acute bladder toxicity and one patient $(3.45 \%)$ had grade 2 acute toxicity. Late bladder toxicity was grade 1 in 5 patients (17.24\%), grade 2 in 3 patients (10.34\%) and grade 3 in 1 patient (3.45\%). Late rectal toxicity, grade 2 in 3 patients (10.34\%), grade 3 in 1 patient, was noted. Overall survival at 2 years was $100 \%$ and $89.65 \%$ at 5 years. Relapse-free survival at 2 years was $82.76 \%$ and $62.07 \%$ at 5 years. There were 3 deaths (10.34\%) of which only one was related to prostate cancer. Conclusion:

*The first two authors contribute equally. 
Radiotherapy, like surgery, is a fundamental option for the treatment of prostate cancers, particularly those that are locally advanced. It is gaining in importance with the improvement of techniques (IMRT, VMAT...) and new fractionations which contribute to the reduction of toxicities and the comfort of patients (shorter spread).

\section{Keywords}

Prostate Cancer, 3D Conformal Radiotherapy, Survival

\section{Introduction}

Prostate cancer is the second most diagnosed cancer in men after lung cancer with $13.7 \%$ of cases. It ranks first in terms of incidence in men over 55 years of age [1]. Mortality has been decreasing steadily since 1990, with the rate standardised on the world population falling from 18.1 to 10.2 per 100,000 HA between 1990 and 2012, thanks to improved treatment and access to screening for early diagnosis [2].

In Guadeloupe, over the period 2008-2012, the incidence and mortality were respectively 192.9 and 25.1 per 100,000 HA [3].

Its management is multidisciplinary, with surgery and radiotherapy as the main curative means. Thanks to the progress made by conformal radiotherapy, the results obtained are becoming similar in terms of disease control to those of surgery, as shown by several comparative series. Radiotherapy has therefore become a real alternative to surgery and should be offered to any patient with prostate cancer [4].

Despite the important advances, the availability of techniques is rather heterogeneous.

We report the epidemiological, clinical, therapeutic and prognostic results of patients treated with 3D conformal radiotherapy for prostate adenocarcinoma located at the University Hospital of Pointe-à-Pitre in Guadeloupe.

\section{Materials and Methods}

\subsection{Study Setting}

We conducted our study in the radiotherapy department of the Pointe-à-Pitre University Hospital, which is the only radiotherapy centre on the island.

During the period of our study (2015), the department had two Varian linear accelerators (clinac ${ }^{\circledR}$ ix and clinac ${ }^{\circledR} 2100$ ).

\subsection{Type of Study and Period}

This was a retrospective descriptive study of prostate cancer cases treated at the radiotherapy department of the University Hospital of Pointe-à-Pitre (Guadeloupe) over the period January 2015-December 2015. 


\subsection{Study Population}

\section{Inclusion criteria}

- Non-metastatic prostate cancer treated with radiotherapy \pm hormone therapy.

- Absence of any previous specific treatment for prostate cancer.

- Patients were selected according to whether the intake was entirely public that's why the number of patients is small.

\section{Non-inclusion criteria}

- Incomplete file or patient lost to follow-up

- All privately treated patients were excluded

- Treatment: Radiation therapy is said to be conformal when the dose of ionising radiation used is delivered homogeneously to a precisely defined tumor volume while sparing the surrounding healthy tissue and organs. A initial three-dimensional imaging for location and repositioning is used. The precise calculation of the dose to be delivered is achieved by computer-controlled multi-blade collimators.

\subsection{Data Collection}

The data was collected using archived medical records, from Aria software of Varian and Easily from CHU Guadeloupe. A data collection form was drawn up for this purpose.

\subsection{Methods of Analysis}

Data were entered and analysed in Epi info 7 on Microsoft Excel 2007.

Histograms and other figures were made with Microsoft Excel 2007.

For the quantitative variables (age, PSA, dose, follow up...) we assessed the minimum, maximum, mean and standard deviation. For all qualitative variables, the calculation of frequency and percentage was performed.

The Kaplan-Meier method was used for the survival curves at 2 and 5 years.

\subsection{Ethical Considerations}

We collected data using anonymised forms with strict confidentiality.

\section{Results}

The characteristics of the patients are summarized in Table 1. 29 patients were collected over a one-year period. All were treated with radiotherapy \pm hormone therapy. The mean age of the patients was 72.7 years, with a minimum of 54 years and a maximum of 83 years. The median age was 75 years. The most representative comorbidity was hypertension in 23 patients $(79.31 \%)$. The main discovery circumstance was routine screening in 19 patients (65.52\%). Rectal examination was abnormal in 15 patients (51.72\%). The median PSA level was $12 \mathrm{ng} / \mathrm{ml}$ with a range of 3.05 to $79 \mathrm{ng} / \mathrm{ml}$. Gleason score analysis showed $6 \mathrm{pa}-$ tients $(20.69 \%)$ with a score of $6(3+3), 23$ patients $(79.31 \%)$ with a score of 7 including 12 patients (41.38\%) with grade 3 and 11 patients (37.93\%) with grade 
4. MRI was performed in 26 patients (89.66\%) and was contraindicated in 3 patients. It revealed a capsular breakthrough (T3a) in 5 patients (19.23\%), seminal vesicle involvement (T3b) in 4 patients (15.38\%) and lymph node involvement in 1 patient $(3.8 \%)$. CT scans were performed in 9 patients $(31.03 \%)$ and scintigraphy in 25 patients (86.21\%). There were no distant locations. The D'AMICO classification found 3 patients (10.34\%) classified as low risk, 14 patients (48.28\%) as high risk and 12 patients (41.38\%) as intermediate risk. All our patients had received 3D conformal radiotherapy for curative purposes. It was combined or not with hormone therapy. The median time to treatment was 5.7 months (2.3 23). Pelvic irradiation was performed in 15 patients $(51.72 \%)$. The median total dose delivered was $74 \mathrm{~Gy}$, with extremes of $70 \mathrm{~Gy}$ for the minimum and $76 \mathrm{~Gy}$ for the maximum. In all our patients, a classical fractionation was used, i.e. 2 Gy per fraction, 5 days a week. Hormone therapy was combined with radiotherapy in 17 patients (58.62\%). All patients in the D'AMICO high-risk group received long hormonal therapy and 3 patients in the intermediate-risk group received short hormonal therapy. At the end of treatment, patients were seen in consultation 2 to 3 months later and then once a year, alternating with the referring urologist, with a PSA level. The median follow-up after radiotherapy was 56 months (28 66). The median follow-up was 63 months (27.5 - 74.3). Toxicities were assessed according to RTOG criteria. Acute toxicity was defined as all toxicities occurring during treatment and up to 3 months after the end of treatment and all those occurring beyond 3 months were late. Seven patients (24.14\%) had grade 1 acute bladder toxicity and one patient (3.45\%) had grade 2 acute toxicity. All patients had tolerated treatment well in terms of digestion, with grade 1 symptoms in seven patients (24.14\%). Late bladder toxicity was grade 1 in 5 patients (17.24\%), grade 2 in 3 patients (10.34\%) and grade 3 in 1 patient (3.45\%). Late rectal toxicity, grade 2 in 3 patients (10.34\%), grade 3 in 1 patient, was noted. Biological remission was achieved in 28 patients (96.55\%), with only one patient showing biological progression. The median time to nadir was 23.5 months (2-52). During the follow-up, biological relapse was noted in 7 patients (24.14\%) associated in 2 patients with a local focus on exploration (PET-choline) and in 3 patients with secondary bone locations. Overall survival at 2 years was $100 \%$ and $89.65 \%$ (26 patients) at 5 years (Figure 1). Relapse-free survival at 2 years was $82.76 \%$ (24 patients) and $62.07 \%$ (18 patients) at 5 years (Figure 2). There were 3 deaths (10.34\%) of which only one was related to prostate cancer and the other 2 to pancreatic cancer and biliary cancer respectively.

\section{Discussion}

Prostate cancer is the most common cancer in France, accounting for $16 \%$ of all cancer cases and $28 \%$ of cases in men. The number of new cases observed in 2011 was 53,917 [2].

In the French West Indies, the incidence of prostate cancer and its mortality are higher than in metropolitan France (50\% of incident male cases 140/100,000), this is related to the African ethnic origin of the majority of this island population 


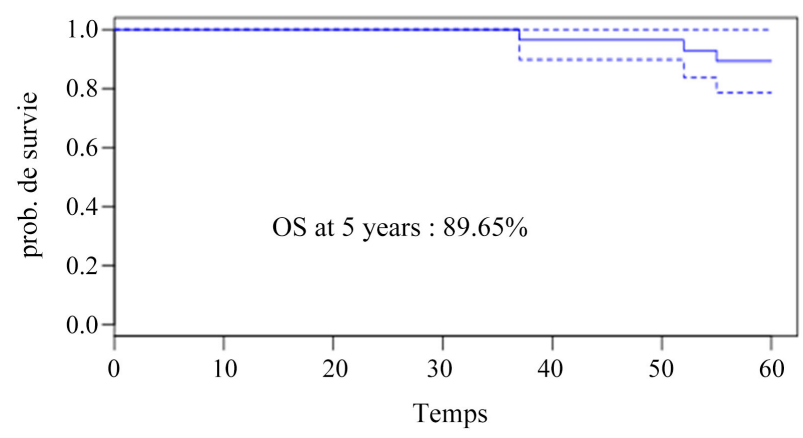

Figure 1. 5-year overall survival curve.

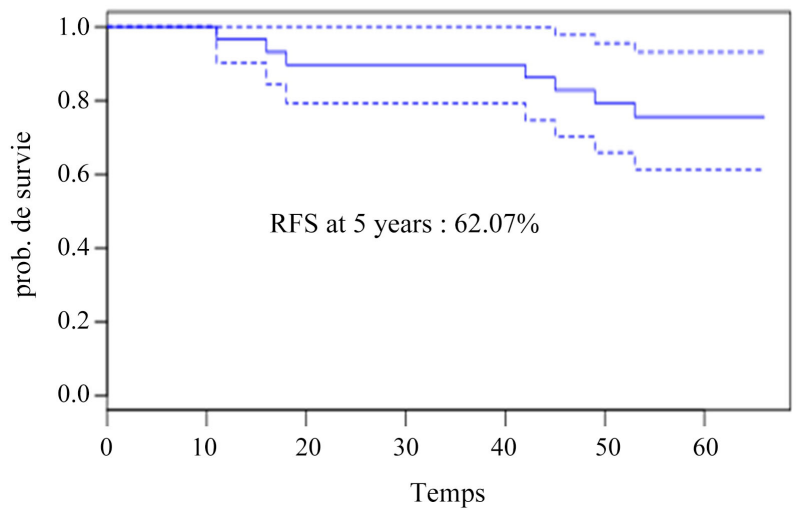

Figure 2. Relapse-free survival curve at 5 years.

Table 1. Characteristics of patients with localized prostate cancer.

\begin{tabular}{cc}
\hline Characteristics of patients & headcount (percent) \\
\hline Median age (years) & $75(54-83)$ \\
HTA & $23(79.31 \%)$ \\
Diabetes & $12(41.38 \%)$ \\
heart disease & $3(10.34 \%)$ \\
CRI & $1(3.45 \%)$ \\
Systematic screening & $19(65.52 \%)$ \\
Urinary signs & $10(34.48 \%)$ \\
Performance status & \\
0 & $20(69 \%)$ \\
1 & $8(28 \%)$ \\
2 & $1(3 \%)$ \\
TR abnormal & $15(51.72 \%)$ \\
Median PSA (ng/ml) & $12(3.05-79)$ \\
Gleason & \\
$-6(3+3)$ & $6(20.69 \%)$ \\
-7 (3 + 4) & $12(41.38 \%)$ \\
$-7(4+3)$ & $11(37.93 \%)$ \\
Classification of D'AMICO & $14(48.28 \%$ \\
- Low risk & $3(10.34 \%)$ \\
-Middle risk & $12(41.38 \%)$ \\
\hline
\end{tabular}

CRI: Chronic renal insufficiency, PSA: prostate specific antigen, TR: rectal touch, HTA: high blood pressure. 
and probably to environmental pollution by chlordecone [5].

The average age at diagnosis is 70 years $(54,55)$. In sub-Saharan Africa, in the series by M. NDOYE [6] and M. GUEYE [7], the mean age was 71 and 69 years respectively. In our study, the mean age was 72.68 years.

Prostate cancer screening remains controversial. This controversy has been reinforced by the apparently conflicting specific mortality results of the 2 largest randomised studies: PLCO and ERSPC [8] [9]. However, prostate cancer screening has proven its ability to decrease disease-specific mortality. In our study, the main finding was individual screening in 19 patients (65.52\%). This last result could be explained by the high prevalence of prostate cancer in the French West Indies.

All our patients had adenocarcinoma with a Gleason score of 7 in $69.31 \%$ of the population. In Mouhamadou Bachir Ba's study, 35.5\% had a Gleason score of 7. However, the majority of his patients (70.9\%) were at high risk of AMICO compared to $48.28 \%$ in our series [10].

Prostate MRI is a powerful examination for the detection of so-called "significant" lesions. Multiparametric MRI offers the greatest accuracy in the diagnosis and staging of prostate cancer [11] [12]. Its place before biopsy is suggested by Fourcade et al. who concluded that pre-biopsy prostate MRI and the PIRADS score appear to be good predictive tools for the diagnosis and assessment of prostate cancer aggressiveness. In addition to aiding diagnosis and extension assessment, MRI has an important role in defining target volumes.

It was performed in 26 patients (29.66\%) in our series with informative results on local extension. Bone scintigraphy is the reference examination for the detection of bone metastasis [13]. The sensitivities and specificities of scintigraphy reach more than $90 \%$ - 95\%, especially since the appearance of hybrid cameras, which make it possible to carry out a tomoscintigraphy (SPECT or Single Photon Emission Computed Tomography) coupled with a bone scan. The sensitivity of the bone scan depends mainly on the PSA level. It detects metastases significantly from a PSA threshold $>20 \mathrm{ng} / \mathrm{ml}$. In our series, 25 patients (86.21\%) were scanned.

Radiotherapy plays a key role in the therapeutic management of patients with prostate cancer at different stages of progression. This role has been further strengthened by a better understanding of radiobiology and technical advances that allow the delivery of larger doses with fewer side effects.

$3 \mathrm{D}$ conformal radiotherapy followed on from 2D radiotherapy, and had allowed an increase in the dose to the prostate to 74 Gy. DEARNALEY et al. [14] compared a conformal technique with a conventional technique in 225 patients at a dose of $64 \mathrm{~Gy}$. There was no significant difference in bladder toxicity, however rectal toxicity was a determining and limiting factor $56 \%$ grade 1 rectitis versus $37 \%$ and $12 \%$ versus $3 \%$ for grade 2 .

No significant difference was observed in local control or overall survival [14].

The constant evolution of techniques has made conformal radiotherapy with intensity modulation (IMRT) the technique indicated for the treatment of pros- 
tate cancer. IMRT reduces late toxicity compared with conventional RT at equivalent dose and increases the dose delivered to the tumour without significantly increasing toxicity [15].

However, in developing countries, 3D conformal radiotherapy is the most widely used technique.

The PROTECT trial, with more than $20 \%$ of patients presenting with intermediate stage at diagnosis, confirms the equivalence in specific survival between surgery and irradiation at 10 years.

In 2015, all 29 patients in our series had been treated with 3D conformal radiotherapy combined with hormone therapy in 17 patients $(58.62 \%)$.

Lymph node irradiation has shown discordant results with no demonstrated benefit in the two phase III trials specifically evaluating its value (GETUG P01; RTOG94-13) (evidence level 2). Randomised trials demonstrating the value of irradiation in high-risk or locally advanced tumours have all included lymph node irradiation [15].

Pelvic irradiation concerned $51.72 \%$ of patients compared with $16.8 \%$ in the Pontvert study [16].

Hypofractionation is a real alternative with an enormous gain in machine time. In the high-risk group, an Italian study randomised 168 patients in a phase III trial to fractionated prostate RT at $80 \mathrm{~Gy}$ (2 Gy per fraction) compared with hypofractionated RT at $62 \mathrm{~Gy}$ (3.1 Gy per fraction) combined with 9 months of HT [17]. SSRB favoured hypofractionated therapy at 3 years ( $87 \%$ vs $79 \%, p=$ 0.035 ) in an initial analysis [17]. In a more recent publication with a follow-up of 70 months, neither local nor distant control was significantly improved in the hypofractionated arm compared with fractionated RT. The SSRB was improved by $10.2 \%$ but not significantly ( $85 \%$ vs $74 \%, p=0.065)$ [17]. The English Conventional or Hypofractionated Highdose Intensity Modulated

Radiotherapy in Prostate Cancer (CHHiP) trial randomised over $12 \%$ of highrisk patients to a non-inferiority comparison of $\mathrm{RT}$ without pelvic irradiation between a standard $74 \mathrm{~Gy} / 2 \mathrm{~Gy}$ per fraction regimen and two hypofractionated doses of 60 Gy and 57 Gy at 3 Gy per session [18]. Neoadjuvant and concurrent (3 - 6 months) HT could be combined. The efficacy results for patients $<75$ years ( $85 \%$ of the population) in BRSC at 5 years are relatively similar between arms, $88.9 \%, 90.5 \%$ and $85.5 \%$ for 74,60 and 57 Gy respectively [18].

Hormone therapy was superior to exclusive RT for local control, biochemical control, metastasis and overall survival at 10 years in the EORTC study: $40 \%$ vs $58 \%(\mathrm{p}=0.0004)$; RTOG $85-31: 38 \%$ vs $47 \%$ ( $\mathrm{p}=0.0043)$ [19] [20].

The indication for hormone therapy was met in patients in the intermediate unfavourable and high risk groups. Patients in the intermediate-favourable group only received exclusive radiotherapy. Indeed, Zumsteg et al. reported that patients in the intermediate group without poor prognostic factors (Gleason $3+4$, less than $50 \%$ positive biopsies) had an excellent outcome when treated with exclusive radiotherapy [21]. 
Radiotherapy was well tolerated by patients, with no acute urinary or digestive toxicity of grade $>2$ noted in our series. Indeed, acute urinary toxicity grade 1 and 2 were respectively $24.14 \%$ and $3.45 \%$ and digestive toxicity was grade 1 in 10 patients (34.48\%). These results are lower than those reported by Pollack, Beckendorf and Peeters, which could be explained by the small number of patients [22] [23]. Late toxicity was relatively lower than in the literature.

The 5-year relapse-free survival in our series was $62.07 \%$, which is comparable to that reported by Bolla, Mottet and Afshin of $75 \%, 64.7 \%$ and $65.1 \%$ respectively [24] [25].

Regarding 5-year overall survival, Bolla reported an OS of 78\% and the RTOG 92-02 trial (phase III), conducted by Hanks et al., reported an OS of 80\% [24] [26]. The overall survival at 5 years was $89.65 \%$ in our study.

The limitations of our study lie in the fact that it is a retrospective series with a small number of patients.

Nevertheless, our series shows that 3D radiotherapy, apart from toxicities, gives good results in local control and survival.

\section{Conclusion}

Radiotherapy, like surgery, is a fundamental option for the treatment of prostate cancers, particularly those that are locally advanced. It is gaining in importance with the improvement of techniques (IMRT, VMAT...) and new fractionations which contribute to the reduction of toxicities and to the comfort of patients (shorter spread).

\section{Conflicts of Interest}

The authors declare no conflicts of interest regarding the publication of this paper.

\section{References}

[1] Bray, F., Ferlay, J., Soerjomataram, I., Siegel, R.L., Torre, L.A. and Jemal, A. (2018) Global Cancer Statistics 2018: GLOBOCAN Estimates of Incidence and Mortality Worldwide for 36 Cancers in 185 Countries. CA: A Cancer Journal for Clinicians, 68 , 394-424. https://doi.org/10.3322/caac.21492

[2] INCA-Les cancers en France [Internet]. https://www.e-cancer.fr/ressources/cancers en france/index.html?page=7

[3] Article-Bulletin épidémiologique hebdomadaire [Internet]. http://beh.santepubliquefrance.fr/beh/2016/39-40/2016 39-40 $6 . \mathrm{html}$

[4] Hennequin, C., Quero, L., Soudi, H., Sergent, G. and Maylin, C. (2006) Radiothérapie conformationnelle du cancer de la prostate: Technique et résultats. Annales d Uro logie, 40, 233-240. https://doi.org/10.1016/j.anuro.2006.03.003

[5] Multigner, L., Ndong, J.R., Giusti, A., Romana, M., Delacroix-Maillard, H., Cordier, S., et al. (2010) Chlordecone Exposure and Risk of Prostate Cancer. Journal of Clinical Oncology, 28, 3457-3462. https://doi.org/10.1200/JCO.2009.27.2153

[6] Ndoye, M., Niang, L., Gandaho, K.I., Jalloh, M., Labou, I. and Gueye, S. (2014) Advanced Prostate Cancer in Senegal. Clinical Aspects at the General Hospital of 
Grand Yoff. Progrès en Urologie, 24, 271-275. https://doi.org/10.1016/j.purol.2013.08.317

[7] Gueye, S.M., Jalloh, M., Labou, I., Niang, L., Kane, R. and Ndoye, M. (2004) Profil clinique du cancer de la prostate au Sénégal. African Journal of Urology, 10, 203-207.

[8] Smith, J.A. (2012) Commentary on "Prostate Cancer Screening in the Randomized Prostate, Lung, Colorectal, and Ovarian Cancer Screening Trial: Mortality Results after 13 Years of Follow-Up”. Andriole GL, Crawford ED, Grubb RL III, Buys SS, Chia D, Church TR, Fouad MN, Isaacs C, Kvale PA, Reding DJ, Weissfeld JL, Yokochi LA, O'Brien B, Ragard LR, Clapp JD, Rathmell JM, Riley TL, Hsing AW, Izmirlian G, Pinsky PF, Kramer BS, Miller AB, Gohagan JK, Prorok PC; PLCO Project Team. Collaborators (18) Buring JE, Alberts D, Carter HB, Chodak G, Hawk E, Malm H, Mayer RJ, Piantadosi S, Silvestri GA, Thompson IM, Westhoff CL, Kahn JP, Levin B, DeMets D, O'Fallon JR, Porter AT, Ashton MM, Black WC, Division of Urologic Surgery, Washington University School of Medicine, St. Louis, MO 63130, USA: J. Natl Cancer Inst 2012; 104(2): 125-32. Epub January 6, 2012. Urologic Oncology, 30, 960-961. https://doi.org/10.1016/j.urolonc.2012.08.006

[9] Schröder, F.H., Hugosson, J., Roobol, M.J., Tammela, T.L.J., Ciatto, S., Nelen, V., et al. (2012) Prostate-Cancer Mortality at 11 Years of Follow-Up. The New England Journal of Medicine, 366, 981-990. https://doi.org/10.1056/NEJMoa1113135

[10] Ba, M.B., Diallo, A.I., Sarr, F.N., Baldé, E.H.A., Thiam, I. and Gaye, P.M. (2020) Conformational Radiotherapy of Prostatic Adenocarcinoma at the Dalal Jamm Hospital, Senegal-(Retrospective Analysis of a Series of 62 Cases). Journal of Cancer Therapy, 11, 631-638. https://doi.org/10.4236/jct.2020.1110053

[11] Imagerie du cancer de la prostate: IRM et imagerie nucléaire [Internet]. https://www.urofrance.org/basebibliographique/imagerie-du-cancer-de-la-prostateirm-et-imagerie-nucleaire

[12] Bonekamp, D., Jacobs, M.A., El-Khouli, R., Stoianovici, D. and Macura, K.J. (2011) Advancements in MR Imaging of the Prostate: From Diagnosis to Interventions. RadioGraphics, 31, 677-703. https://doi.org/10.1148/rg.313105139

[13] Bastian, P.J., Carter, B.H., Bjartell, A., Seitz, M., Stanislaus, P., Montorsi, F., et al. (2009) Insignificant Prostate Cancer and Active Surveillance: From Definition to Clinical Implications. European Urology, 55, 1321-1332. https://doi.org/10.1016/j.eururo.2009.02.028

[14] Dearnaley, D.P., Khoo, V.S., Norman, A.R., Meyer, L., Nahum, A., Tait, D., et al. (1999) Comparison of Radiation Side-Effects of Conformal and Conventional Radiotherapy in Prostate Cancer: A Randomised Trial. The Lancet (London, England), 353, 267-272. https://doi.org/10.1016/S0140-6736(98)05180-0

[15] Rozet, F., Hennequin, C., Beauval, J.-B., Beuzeboc, P., Cormier, L., Fromont-Hankard, G., et al. (2018) Recommandations françaises du Comité de Cancérologie de l'AFUActualisation 2018-2020: Cancer de la prostate. Progrès en Urologie, 28, R81-R132. https://doi.org/10.1016/j.purol.2019.01.007

[16] Pontvert, D., Gaboriaud, G., Flam, T., Jourdan-da Silva, N., Thiounn, N., Mammar, H., et al. (2008) Radiothérapie conformationnelle à 76 Gy des cancers localisés de la prostate. Modalités thérapeutiques et résultats préliminaires. Cancer Radiotherapie, 12, 78-87. https://doi.org/10.1016/j.canrad.2007.11.002

[17] Arcangeli, G., Saracino, B., Gomellini, S., Petrongari, M.G., Arcangeli, S., Sentinelli, S., et al. (2010) A Prospective Phase III Randomized Trial of Hypofractionation versus Conventional Fractionation in Patients with High-Risk Prostate Cancer. International Journal of Radiation Oncology, Biology, Physics, 78, 11-18. https://doi.org/10.1016/j.ijrobp.2009.07.1691 
[18] Wilson, J.M., Dearnaley, D.P., Syndikus, I., Khoo, V., Birtle, A., Bloomfield, D., et al. (2018) The Efficacy and Safety of Conventional and Hypofractionated HighDose Radiation Therapy for Prostate Cancer in an Elderly Population: A Subgroup Analysis of the CHHiP Trial. International Journal of Radiation Oncology, Biology, Physics, 100, 1179-1189. https://doi.org/10.1016/j.ijrobp.2018.01.016

[19] Bolla, M., Van Tienhoven, G., Warde, P., Dubois, J.B., Mirimanoff, R.-O., Storme, G., et al. (2010) External Irradiation with or without Long-Term Androgen Suppression for Prostate Cancer with High Metastatic Risk: 10-Year Results of an EORTC Randomised Study. The Lancet Oncology, 11, 1066-1073.

https://doi.org/10.1016/S1470-2045(10)70223-0

[20] Souhami, L., Bae, K., Pilepich, M. and Sandler, H. (2009) Impact of the Duration of Adjuvant Hormonal Therapy in Patients with Locally Advanced Prostate Cancer Treated with Radiotherapy: A Secondary Analysis of RTOG 85-31. Journal of Clinical Oncology, 27, 2137-2143. https://doi.org/10.1200/JCO.2008.17.4052

[21] Zumsteg, Z.S., Spratt, D.E., Pei, I., Zhang, Z., Yamada, Y., Kollmeier, M., et al. (2013) A New Risk Classification System for Therapeutic Decision Making with Intermediate-Risk Prostate Cancer Patients Undergoing Dose-Escalated External-Beam Radiation Therapy. European Urology, 64, 895-902. https://doi.org/10.1016/j.eururo.2013.03.033

[22] Pollack, A., et al. (2002) Prostate Cancer Radiation Dose Response: Results of the M. D. Anderson Phase III Randomized Trial. International Journal of Radiation Oncology, Biology, Physics, 53, 1097-1105. https://pubmed.ncbi.nlm.nih.gov/12128107

[23] Peeters, S.T.H., Heemsbergen, W.D., van Putten, W.L.J., Slot, A., Tabak, H., Mens, J.W., et al. (2005) Acute and Late Complications after Radiotherapy for Prostate Cancer: Results of a Multicenter Randomized Trial Comparing 68 Gy to 78 Gy. International Journal of Radiation Oncology, Biology, Physics, 61, 1019-1034. https://doi.org/10.1016/j.ijrobp.2004.07.715

[24] Bolla, M., Collette, L., Blank, L., Warde, P., Dubois, J.B., Mirimanoff, R.-O., et al. (2002) Long-Term Results with Immediate Androgen Suppression and External Irradiation in Patients with Locally Advanced Prostate Cancer (an EORTC Study): A Phase III Randomised Trial. The Lancet (London, England), 360, 103-106. https://doi.org/10.1016/S0140-6736(02)09408-4

[25] Rakhsha, A., Kashi, A.S.Y., Mofid, B. and Houshyari, M. (2015) Biochemical Progression Free Survival in Localized Prostate Cancer Patients Treated with Definitive External Beam Radiotherapy. Electronic Physician, 7, 1330-1335.

[26] Hanks, G.E., Pajak, T.F., Porter, A., Grignon, D., Brereton, H., Venkatesan, V., et al. (2003) Phase III Trial of Long-Term Adjuvant Androgen Deprivation after Neoadjuvant Hormonal Cytoreduction and Radiotherapy in Locally Advanced Carcinoma of the Prostate: The Radiation Therapy Oncology Group Protocol 92-02. Journal of Clinical Oncology, 21, 3972-3978. https://doi.org/10.1200/JCO.2003.11.023 